\title{
Regulation of Transforming Growth Factor- $\beta 1$ Activation and Expression in the Tissue Remodeling Involved in Chronic Rhinosinusitis
}

\author{
Wei Kou ${ }^{a}$ Guo-Hua Hu ${ }^{a}$ Hong-Bing Yao ${ }^{b}$ Xiao-qiang Wang ${ }^{a}$ Yang Shen $^{a}$ \\ Hong-Yong Kang ${ }^{\text {a }}$ Su-Ling Hong ${ }^{\text {a }}$ \\ a Department of Otorhinolaryngology-Head and Neck Surgery, The First Affiliated Hospital of Chongqing Medical \\ University, and bepartment of Otolaryngology, The Children's Hospital of Chongqing Medical University, \\ Chongqing, China
}

\section{Key Words}

Chronic rhinosinusitis $\cdot$ Tissue remodeling $\cdot$ Transforming growth factor- $\beta 1 \cdot$ Dysregulation

\begin{abstract}
Transforming growth factor- $\beta 1$ (TGF- $\beta 1$ ) plays a key role in the tissue remodeling processes involved in chronic rhinosinusitis (CRS), with the biological functions of secreted TGF$\beta 1$ regulated by multiple proteins. Among these regulators, latency-associated peptide and latent TGF- $\beta$-binding protein inhibit TGF- $\beta 1$ function, whereas different proteases and integrins activate it. Progress in understanding the factors responsible for the bioactivity and expression of TGF- $\beta 1$ has revealed that the dysregulation of TGF- $\beta 1$ activation and expression is closely associated with the chronic respiratory inflammatory diseases involved in CRS. This review of the regulation of TGF- $\beta 1$ activation and expression provides insight into the mechanism responsible for the different CRS subtypes, which will help further the investigation of novel therapy targets for the treatment of CRS.
\end{abstract}

Copyright $\odot 2012$ S. Karger AG, Basel

\section{KARGER}

Fax +41613061234 E-Mail karger@karger.ch www.karger.com
(C) 2012 S. Karger AG, Base

0301-1569/12/0743-0172\$38.00/0

Accessible online at:

www.karger.com/orl

\section{Introduction}

Chronic rhinosinusitis (CRS) is a chronic inflammatory disease involving the mucosa of the nasal cavity and sinuses, and shows a prevalence of up to $12.5 \%$ in the population. CRS results in a substantial burden in terms of health, quality of life, and economical expenditure [1, 2]. Hence, a great deal of attention has been focused on the pathogenesis of this disease in an effort to develop effective strategies for improving treatment outcomes.

Remodeling is crucial for wound healing in organs, but a pathological reestablishment process can lead to the formation of aberrant tissues, including in CRS. Based on the tissue remodeling characteristics, CRS can be classified into CRS with nasal polyps (CRSwNP), which is characterized by pseudocyst formation, or without nasal polyps (CRSsNP), which consists of the excessive deposition of collagen by the nasal mucosa [3,4] (fig. 1).

Transforming growth factor- $\beta 1$ (TGF- $\beta 1$ ) plays a key role in the remodeling process of tissues through promoting the differentiation of fibroblasts into myofibroblasts. This latter cell type then synthesizes extracellular matrix proteins $[5,6]$. Adequate TGF- $\beta 1$, primarily in its inactive form, is stored in the extracellular matrix, but must expe-

Su-Ling Hong

Department of Otorhinolaryngology-Head and Neck Surgery

The First Affiliated Hospital of Chongqing Medical University

Chongqing, 400016 (China)

Tel. +861321239 5698, E-Mail entweiweidoctor@yahoo.cn 

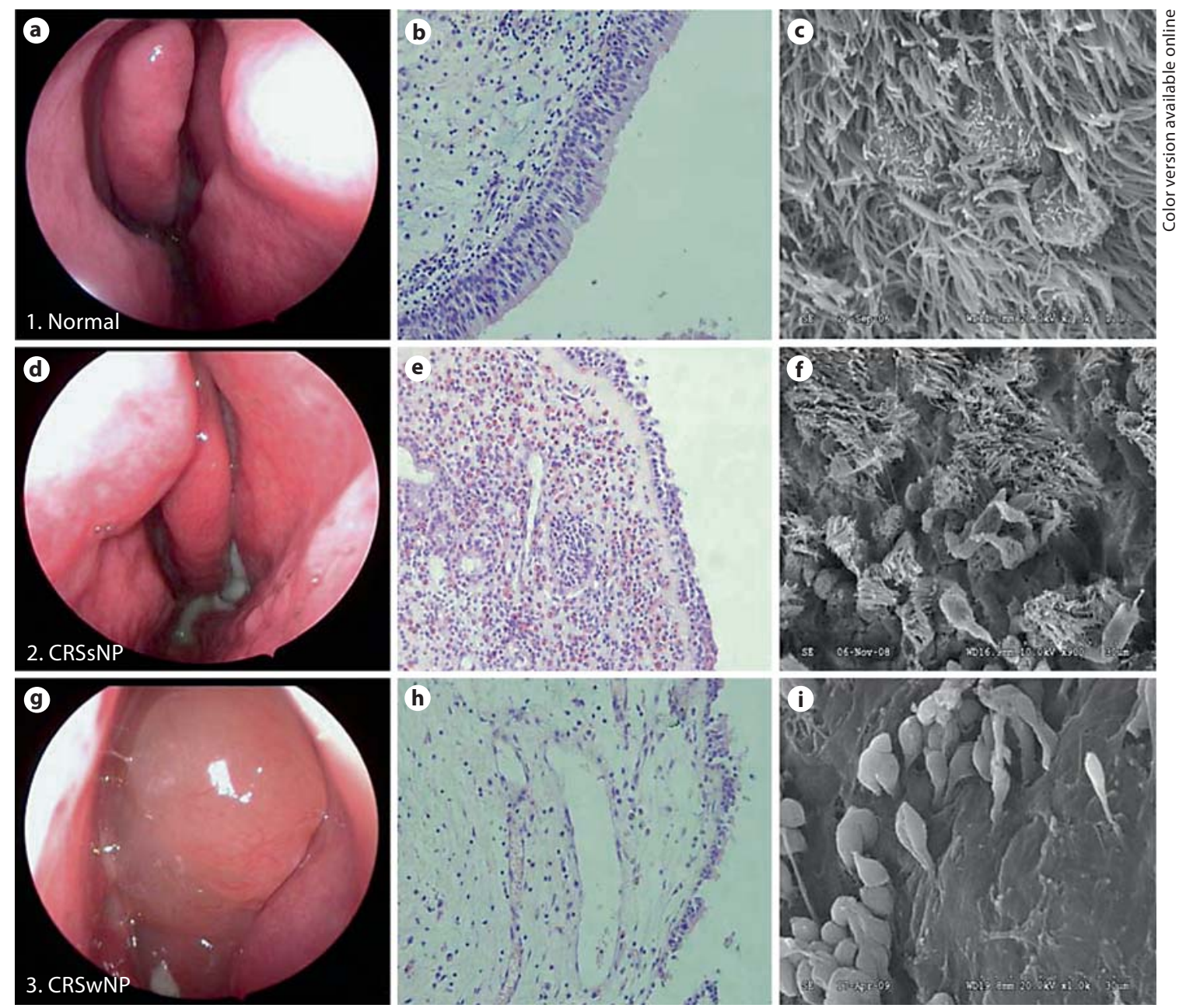

Fig. 1. The comparison of tissue remodeling among tissues from patients with different CRS subtypes and normal controls. Nasal endoscopy: normal = the nasal mucosa is morphologically normal and smooth, with no polypoid neoplasm or purulent secretions; CRSsNP = a large amount of white purulent discharge is flowing out of the nasal sinuses into the middle nasal meatus and posterior naris; $\mathrm{CRSwNP}=$ a large amount of semitransparent and pink polypoid neoplasm with purulent discharge is present. Tissue sections staining: normal = ciliated columnar epithelial cells are separated from the thick lamina propria by a thin layer of basement membrane, which lacks cellular components (the lamina propria consists of connective tissue and lymphocytes, plasma cells, macrophages, and other cells located in the superficial layer of the subepithelium); $\mathrm{CRSsNP}=$ epithelial cell loss, cilia damage, thickened basement membrane, subepithelial collagen deposition, and inflammatory cell infiltration; $\mathrm{CRSwNP}=$ epithelial cell damage, thickened basement membrane, subepithelial edema, pseudocyst formation, a lack of collagen, and the disappearance of glands and blood vessels. HE. $\times 400$. Scanning electron microscope image: normal $(\times 2,500)=$ there are long cilia on the top of the ciliated columnar epithelia cells in the nasal mucosa, arranged in neat rows and swinging in the same direction. CRSsNP $(\times 600)=$ cilia loss, widened gaps between the columnar epithelia cells, which are gathered into bundles lying in different directions; CRSwNP $(\times 1,000)=$ a serious loss of columnar epithelial cells and exposure of a large part of the basement membrane. rience an activation phase before exerting its effects $[7,8]$. Discrepant expression of total TGF- $\beta 1$ (active plus latent forms) can be observed in CRS [3]. Compared to control subjects, patients with CRSsNP show higher levels of TGF- $\beta 1$ expression, whereas those with CRSwNP show lower TGF- $\beta 1$ expression levels. However, despite these correlations, it remains unclear whether the different expression levels and the activation process of TGF- $\beta 1$ are deregulated in CRS tissue remodeling. Hence, elucidating the mechanism responsible for the activation and expression of TGF- $\beta 1$ will be important to answering this question. 


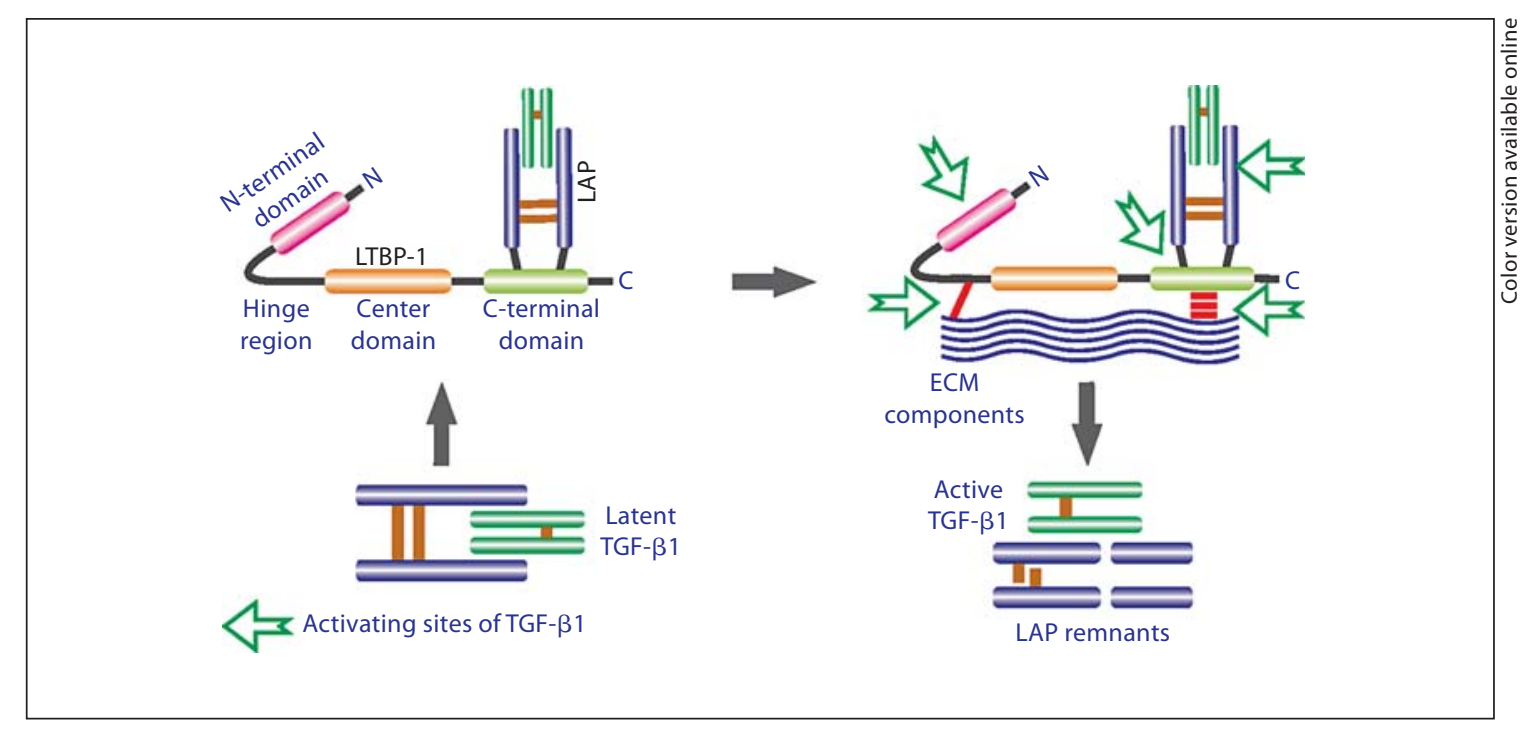

Fig. 2. The construction and extracellular activation of latent TGF- $\beta 1$. The TGF- $\beta 1$ dimer is synthesized intracellularly and combines with LAP to form a latent precursor (SLC). The SLC then forms a LLC with LTBP-1 via covalent bonds. The hollow arrows show the activating sites of TGF- $\beta 1$. Proteases and integrins can activate latent TGF- $\beta 1$ via direct proteolytic cleavage and/or by inducing a conformational change in LAP.

\section{The Dysregulated Activation of TGF- $\beta 1$}

The TGF- $\beta 1$ dimer is synthesized intracellularly and is stored in a latent form outside the cell. Both latencyassociated peptide (LAP) and latent TGF- $\beta$-binding protein (LTBP-1) play an important role in the regulation of TGF- $\beta 1$ by preventing it from exerting its biological functions $[9,10]$. This repression is important for maintaining normal mucosal structure, as evidenced by the presence of only a few active TGF- $\beta 1$ proteins but a substantial amount of nonactive protein in healthy mucosa [11]. However, a significant increase in the active form can be detected in patients with CRS, indicating that the activation of TGF- $\beta 1$ is out of control and is involved in the tissue remodeling process of CRS [12].

Published data have shown that various factors, such as integrins $[13,14]$ and different proteases [15], play key roles in modulating TGF- $\beta 1$ activation through the initiation of LAP and/or LTBP hydrolysis or through conformational changes in LAP that result in TGF- $\beta 1$ liberation (fig. 2 ).

In a study on chronic respiratory inflammatory disease, Tillie-Leblond et al. [16] found that patients with status asthmaticus had dramatically increased levels of MMP-9, a protease that directly cleaves LAP and LTBP-1 to release TGF- $\beta 1$ [17], compared to patients with controlled asthma disorders. Moreover, the levels of active
TGF- $\beta 1$ in the former patients were similarly increased relative to those in the latter patients. The increased TGF$\beta 1$ activity was accompanied by more severe collagen deposition, providing clinical evidence that the dysregulation of TGF- $\beta 1$ activation is closely correlated with airway diseases.

Higher MMP-9 levels are also more present in CRS patients than in healthy controls [18]. In addition, this increase in MMP-9 levels in CRS patients is correlated with an increase in active TGF- $\beta 1$ concentrations. Moreover, MMP-9 levels are increased in CRSwNP relative to those in CRSsNP, so that the activation of TGF- $\beta 1$ is more efficient in patients with CRSwNP [3]. These results provide further understanding of the dysregulation of TGF$\beta 1$ activation involved in the pathogenesis of CRS.

Maiuri et al. [19] investigated the activity of tissue transglutaminase (TG) 2 , a protease involved in TGF- $\beta 1$ activation, in ex vivo cultures of nasal polyp explants from patients and controls. A positive correlation was found between TG2 and the level of active TGF- $\beta 1$. In particular, the specific inhibition of TG2 prevented the process of TGF- $\beta 1$ activation and reduced the quantity of active TGF- $\beta 1$ protein, thereby reducing nasal mucosa restitution [20].

As type I transmembrane receptors, integrins can bind to the extracellular matrix and induce the actin pro- 
tein to contract, thereby inducing conformational changes in LAP and activating TGF- $\beta 1[13,14]$. As well, integrins can aid the membrane type 1-matrix metalloproteinase cleavage of LAP and result in the release TGF- $\beta 1$ [21]. A previous study with several mouse models found that the level of active TGF- $\beta 1$ was higher in the airways of injured mice with increased integrin concentrations when compared to that of normal controls [22]. The increased levels of TGF- $\beta 1$ activity were closely associated with the excessive deposition of collagen in the airway mucosa. McNulty et al. [23] reported that nasal polyp endothelium showed much higher levels of integrins and active TGF- $\beta 1$ than controls and that integrins were involved in the tissue remodeling of CRS through activation of TGF- $\beta 1$. Interestingly, upon the removal of eosinophils in CRS, integrin expression was significantly decreased, which led to the diminished conversion of latent TGF- $\beta 1$ into bioactive TGF- $\beta 1$ and resulted in the alleviation of mucosal fibrosis [24].

These various reports provide the clinical and animal data supporting TGF- $\beta 1$ activation as an important step in maintaining the biological function of this protein. They also show that variation in the concentrations of different TGF- $\beta 1$ activators is one of the mechanisms responsible for the dysregulation of TGF- $\beta 1$ activation in the pathological tissue remodeling processes in the CRS subtypes $[25,26]$. Furthermore, these studies reveal that antiactivator treatments are potentially able to reduce the effects of promoting the mucosa fibrosis exerted by active TGF- $\beta 1$.

\section{The Aryl Hydrocarbon Receptor-LTBP-1-TGF- $\beta 1$ Pathway in the Regulation of TGF- $\beta 1$ Expression in CRS}

Recent published data reveals that the aryl hydrocarbon receptor $(\mathrm{AhR})$, a unique intracellular protein, may play a key role in regulating the expression of TGF- $\beta 1$ through LTBP-1 [27]. AhR can inhibit LTBP-1 transcription via the recruitment of histone deacetylase- 2 to the LTBP-1 promoter, thus maintaining the gene in a repressed state. In addition to binding and maintaining TGF- $\beta 1$ in an inactive form, LTBP-1 is a key factor mediating TGF- $\beta 1 \mathrm{mRNA}$ expression. Hence, in the absence of LTBP-1, the endonuclear synthesis of TGF- $\beta 1$ is impaired, thereby resulting in decreased transcription of TGF- $\beta 1$ [28]. In $\mathrm{AhR}^{-/-}$mice, increased expression of LTBP- 1 is accompanied by the overexpression of TGF- $\beta 1$ mRNA, whereas the activity of proteases such as MMP-9 is decreased. By contrast, mice expressing AhR show decreased TGF- $\beta 1$ synthesis and increased protease activity. Therefore, AhR may have the ability to modulate mucosa structural integrity by regulating TGF- $\beta 1$ expression.

Because of the close relationship between these aforementioned factors, Gomez-Duran et al. [29] suggested that the negative regulatory effects of AhR on LTBP-1 expression may contribute to the inhibition of TGF- $\beta 1$ expression. Moreover, an AhR-LTBP-1-TGF- $\beta 1$ pathway may mediate the progression of disease. AhR downregulation and an associated decreased protease activity have been confirmed in hepatic fibrosis, resulting in the overexpression of TGF- $\beta 1$ in this disease [30]. This observation suggests a possible mechanism to explain the baffling problem in CRS: the discrepancy between TGF- $\beta 1$ expression and its bioavailability in the CRS subtypes.

Noteworthy progress on the role of AhR in CRS has been recently made. Hsu et al. [31] reported that the expression of hypoxia-inducible factor $1 \alpha$, a protein known to function as an AhR-specific nuclear translocator and mediator of AhR target gene expression, was significantly elevated in nasal polyps compared with control tissues. These findings indicate that AhR expression is enhanced in CRSwNP, which suppresses the secretion of TGF- $\beta 1$ protein. Thus, accompanied by improved protease activity, AhR induces higher levels of bioavailable TGF- $\beta 1$ in CRSwNP. By contrast, the reduced expression of AhR may result in the overexpression of TGF- $\beta 1$, which is involved in aggravating the mucosal fibrosis associated with CRSsNP (fig. 3).

The precise role of the AhR-LTBP-1-TGF- $\beta 1$ pathway in the expression of TGF- $\beta 1$ in CRS remains unknown, although several studies can partially explain the contrasting TGF- $\beta 1$ expression in the CRS subtypes and the controls. If a mutually restrictive relationship between AhR and TGF- $\beta 1$ is regulated by this pathway, other pathways are possibly involved in the modulation of TGF- $\beta 1$ expression. Further studies will be needed to gain definitive answers to these questions.

\section{Potential Therapeutic Applications in CRS}

In CRS, the dysregulation of TGF- $\beta 1$ activation and expression is responsible for the pathological restructuring process of the tissue. Therefore, TGF- $\beta 1$ may represent a promising antifibrotic therapeutic target in CRS, holding the potential to ameliorate symptoms in CRS patients. 


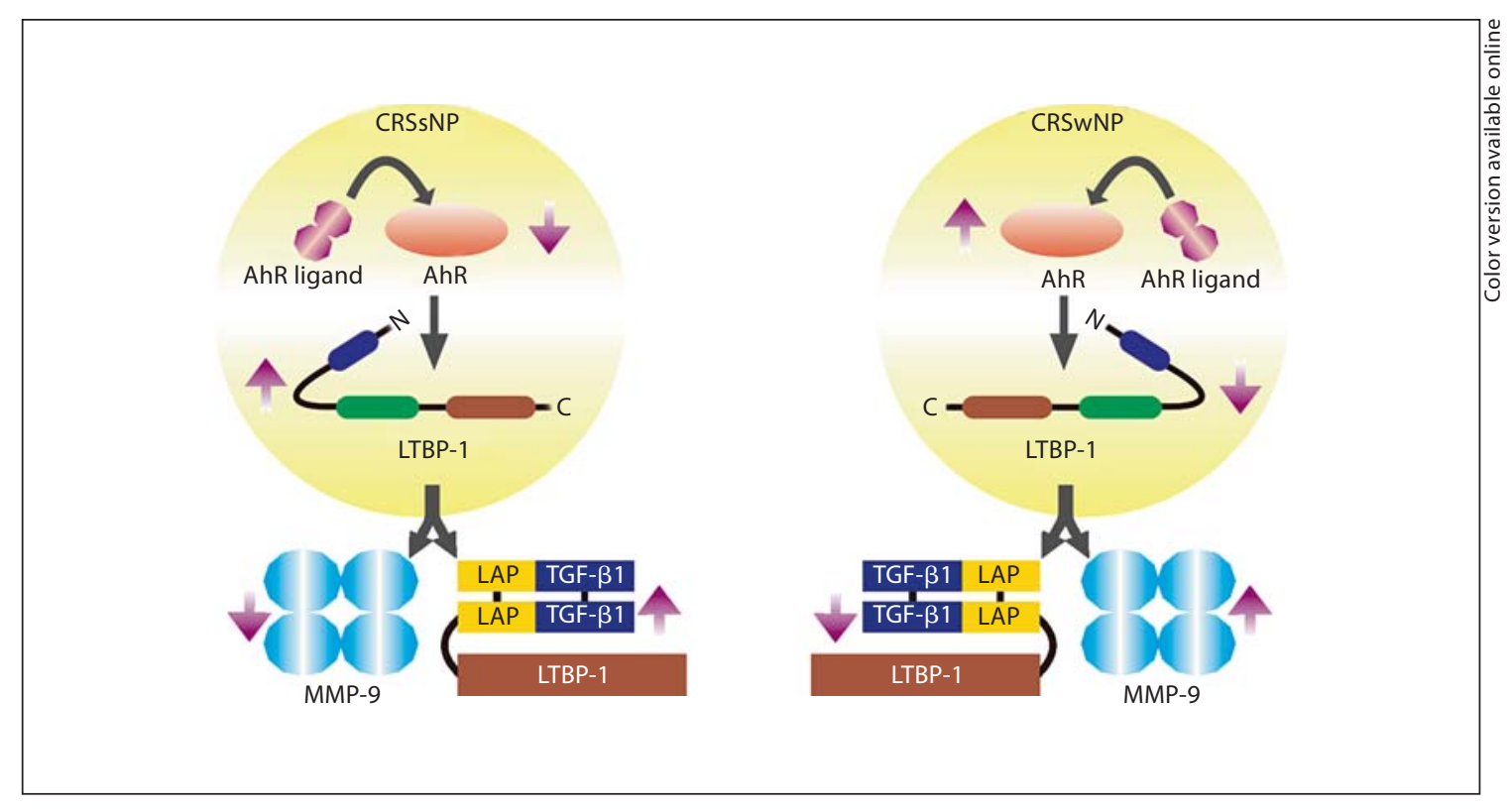

Fig. 3. The AhR-LTBP-1-TGF- $\beta 1$ pathway. The AhR-LTBP-1-TGF- $\beta 1$ pathway in CRS can be explained as follows. The activity of MMP-9 is greatly improved by increasing AhR expression, resulting in high efficiency activation of extracellular TGF- $\beta 1$ in CRSwNP, despite the downregulated LTBP-1 and TGF- $\beta 1$ protein expression. In contrast, the decreased expression of AhR may result in LTBP-1 and TGF- $\beta 1$ overexpression, which could be involved in the mucous fibrosis associated with CRSsNP. However, there would paradoxically be less bioavailable TGF- $\beta 1$ in CRSsNP, owing to the decreased MMP-9 activity.

Corticosteroids are currently the first-line therapy for nasal polyps, as recommended by the European EAACI position paper on rhinosinusitis and nasal polyps, as well as American guidelines [32, 33]. TGF- $\beta 1$-induced fibroblast proliferation and differentiation in nasal polyps have been shown to be suppressed in vitro by corticosteroids [34]. However, to our knowledge, no data have indicated that the use of topical corticosteroids is effective in controlling TGF- $\beta 1$ expression in the upper airway. Further, some patients are nonresponders after treatment with corticosteroids for 3 months and receive a functional endoscopic sinus surgery. The recourse required by these patients implies that the level of TGF- $\beta 1$ is not modulated by corticosteroid treatment, indicating that corticosteroids show no effect on TGF- $\beta 1$ expression in CRS, as suggested by the results of computed tomography/endoscopy, histopathologic examination, and patients' complaints [35-37].

The factors involved in abnormal TGF- $\beta 1$ expression (e.g. integrins) may contribute to a suite of novel therapeutic targets. Accumulating evidence suggests an essential role for integrin-mediated TGF- $\beta 1$ activation in chronic airway inflammatory diseases, during tissue re- modeling, and in immune homeostasis in patients, implying that integrins may represent new targets for antifibrotic therapies. Moreover, some anti-integrin medicines have already been applied in the clinic to inhibit organ fibrosis [38]. Anti-IL-5 treatment has been shown to result in a significant reduction in the number of TGF$\beta 1^{=}$nasal and sinus eosinophils as well as a reduction in the expression of integrins. Consequently, eliminating IL-5 in CRS may decrease the conversion of latent TGF$\beta 1$ into active TGF- $\beta 1$, as well as reduce the local concentrations of TGF- $\beta 1$ in vivo [38]. Specific inhibition of TG2 can also inhibit TGF- $\beta 1$ activation, decrease the quantity of active TGF- $\beta 1$ proteins, and thereby reduce nasal mucosa fibrosis, as shown in nasal polyps using an in vitro cystic fibrosis test $[39,40]$. As a key player in TGF- $\beta 1$ action, LTBP-1 is directly involved in the process of TGF- $\beta 1$ expression and activation. An LTBP-1 antibody can block TGF- $\beta 1$ expression and activation, and is capable of inhibiting stretch-induced collagen mRNA expression. Thus, anti-IL-5, TG2, integrins, and LTBP-1 in combination may offer potential therapeutic strategies against fibrotic disease progression, limiting airway remodeling, and perhaps providing new angles for CRS treatment. 


\section{Conclusions}

TGF- $\beta 1$ is the main switch in tissue remodeling. Importantly, the dysregulation of TGF- $\beta 1$ activation and expression has been shown to be closely associated with chronic respiratory inflammatory diseases, including CRS. The factors affecting the activation of TGF- $\beta 1$ are involved in the TGF- $\beta 1$-mediated remodeling process. CRS biopsies and control samples both express higher levels of TGF- $\beta 2$ than TGF- $\beta 1$, particularly in CRSwNP patients. However, this observation is not consistent with the histopathological characteristics of the CRS subtypes and thereby prompts the questions: 'Is the balance between active and latent TGF- $\beta 2$ also disrupted by dysregulation of TGF- $\beta 2$ activation?' and further, 'What is the role of TGF- $\beta 2$ in the pathogenesis of the CRS subtypes?' Moreover, almost no expression of TGF- $\beta 3$ is observed in the CRS subtypes and the controls, which may suggest that TGF- $\beta 3$ plays a negligible role in CRS tissue remodeling [3]. Further study of the deregulated activation of TGF- $\beta$ s in CRS patients will help determine the mechanism responsible for CRS and lead to the development of novel therapeutic targets, thus improving the treatment of CRS.

\section{References}

1 Zang HR, Wang T, Li YC, Zhang SZ, Fan EZ, Han DM: Value of nasal mucosa congestion index in choosing treatment strategies for chronic rhinosinusitis. Acta Otolaryngol 2009;129:1237-1241.

-2 Hamilos DL: Chronic rhinosinusitis: epidemiology and medical management. J Allergy Clin Immunol 2011;128:693-707, quiz 08-9.

-3 Van Bruaene N, Derycke L, Perez-Novo CA, Gevaert P, Holtappels G, De Ruyck N, et al: TGF-beta signaling and collagen deposition in chronic rhinosinusitis. J Allergy Clin Immunol 2009; 124:253-259, 59 e1-2.

4 Li X, Meng J, Qiao X, Liu Y, Liu F, Zhang N, et al: Expression of TGF, matrix metalloproteinases, and tissue inhibitors in Chinese chronic rhinosinusitis. J Allergy Clin Immunol 2010;125:1061-1068.

5 Thiele A, Holzhausen HJ, Riederer A, Knipping S: Mucosal remodeling in chronic rhinosinusitis without nasal polyposis - an ultrastructural evaluation (in German). Laryngorhinootologie 2010;89:352-357.

6 Zhang N, Liu S, Lin P, Li X, van Bruaene N, Zhang J, et al: Remodeling and inflammation in Chinese versus white patients with chronic rhinosinusitis. J Allergy Clin Immunol 2010;125:507, author reply 507-508.

$\checkmark 7$ Koli K, Saharinen J, Hyytiainen M, Penttinen C, Keski-Oja J: Latency, activation, and binding proteins of TGF-beta. Microsc Res Tech 2001;52:354-362.

8 Santibanez JF, Quintanilla M, Bernabeu C: TGF-beta/TGF-beta receptor system and its role in physiological and pathological conditions. Clin Sci (Lond) 2011;121:233-251

$\checkmark 9$ Isogai Z, Ono RN, Ushiro S, Keene DR, Chen Y, Mazzieri R, et al: Latent transforming growth factor beta-binding protein 1 interacts with fibrillin and is a microfibril-associated protein. J Biol Chem 2003;278:27502757.
10 Rifkin DB: Latent transforming growth factor-beta (TGF-beta) binding proteins: orchestrators of TGF-beta availability. J Biol Chem 2005;280:7409-7412.

>11 Hirschberg A, Jokuti A, Darvas Z, Almay K, Repassy G, Falus A: The pathogenesis of nasal polyposis by immunoglobulin $\mathrm{E}$ and interleukin-5 is completed by transforming growth factor-beta1. Laryngoscope 2003; 113:120-124.

12 Watelet JB, Claeys C, Perez-Novo C, Gevaert $\mathrm{P}$, Van Cauwenberge P, Bachert C: Transforming growth factor betal in nasal remodeling: differences between chronic rhinosinusitis and nasal polyposis. Am J Rhinol 2004;18:267-272.

13 Wipff PJ, Hinz B: Integrins and the activation of latent transforming growth factor beta1 - an intimate relationship. Eur J Cell Biol 2008;87:601-615.

14 Worthington JJ, Klementowicz JE, Travis MA: TGFbeta: a sleeping giant awoken by integrins. Trends Biochem Sci 2011;36:47-54.

15 Jenkins G: The role of proteases in transforming growth factor-beta activation. Int J Biochem Cell Biol 2008;40:1068-1078.

$>16$ Tillie-Leblond I, Pugin J, Marquette $\mathrm{CH}$, Lamblin C, Saulnier F, Brichet A, et al: Balance between proinflammatory cytokines and their inhibitors in bronchial lavage from patients with status asthmaticus. Am J Respir Crit Care Med 1999;159:487-494.

-17 Oshita Y, Koga T, Kamimura T, Matsuo K, Rikimaru T, Aizawa H: Increased circulating $92 \mathrm{kDa}$ matrix metalloproteinase (MMP-9) activity in exacerbations of asthma. Thorax 2003;58:757-760.

18 Lee YM, Kim SS, Kim HA, Suh YJ, Lee SK, Nahm DH, et al: Eosinophil inflammation of nasal polyp tissue: relationships with matrix metalloproteinases, tissue inhibitor of metalloproteinase-1, and transforming growth factor-beta1. J Korean Med Sci 2003;18:97102.
19 Maiuri L, Luciani A, Giardino I, Raia V, Villella VR, D’Apolito M, et al: Tissue transglutaminase activation modulates inflammation in cystic fibrosis via PPARgamma down-regulation. J Immunol 2008; 180: 7697-7705.

20 Rinia AB, Kostamo K, Ebbens FA, van Drunen CM, Fokkens WJ: Nasal polyposis: a cellular-based approach to answering questions. Allergy 2007;62:348-358.

$21 \mathrm{Mu}$ D, Cambier S, Fjellbirkeland L, Baron JL, Munger JS, Kawakatsu H, et al: The integrin alpha(v)beta8 mediates epithelial homeostasis through MT1-MMP-dependent activation of TGF-beta1. J Cell Biol 2002;157:493507.

-22 Munger JS, Huang X, Kawakatsu H, Griffiths MJ, Dalton SL, Wu J, et al: The integrin alpha $\mathrm{v}$ beta 6 binds and activates latent TGF beta 1: a mechanism for regulating pulmonary inflammation and fibrosis. Cell 1999;96:319328.

23 McNulty CA, Symon FA, Wardlaw AJ: Characterization of the integrin and activation steps mediating human eosinophil and neutrophil adhesion to chronically inflamed airway endothelium. Am J Respir Cell Mol Biol 1999;20:1251-1259.

24 Cho JY, Miller M, Baek KJ, Han JW, Nayar J, Lee SY, et al: Inhibition of airway remodeling in IL-5-deficient mice. J Clin Invest 2004; 113:551-560

25 Watelet JB, Bachert C, Claeys C, Van Cauwenberge $\mathrm{P}$ : Matrix metalloproteinases MMP-7, MMP-9 and their tissue inhibitor TIMP-1: expression in chronic sinusitis vs nasal polyposis. Allergy 2004;59:54-60.

26 Spinozzi F, de Benedictis D, de Benedictis FM: Apoptosis, airway inflammation and anti-asthma therapy: from immunobiology to clinical application. Pediatr Allergy Immunol 2008;19:287-295. 
-27 Gomez-Duran A, Ballestar E, Carvajal-Gonzalez JM, Marlowe JL, Puga A, Esteller M, et al: Recruitment of CREB1 and histone deacetylase 2 (HDAC2) to the mouse Ltbp-1 promoter regulates its constitutive expression in a dioxin receptor-dependent manner. J Mol Biol 2008;380:1-16.

28 Walton KL, Makanji Y, Chen J, Wilce MC, Chan KL, Robertson DM, et al: Two distinct regions of latency-associated peptide coordinate stability of the latent transforming growth factor-beta1 complex. J Biol Chem 2010;285:17029-17037.

-29 Gomez-Duran A, Carvajal-Gonzalez JM, Mulero-Navarro S, Santiago-Josefat B, Puga A, Fernandez-Salguero PM: Fitting a xenobiotic receptor into cell homeostasis: how the dioxin receptor interacts with TGFbeta signaling. Biochem Pharmacol 2009;77:700712.

30 Lahvis GP, Lindell SL, Thomas RS, McCuskey RS, Murphy C, Glover E, et al: Portosystemic shunting and persistent fetal vascular structures in aryl hydrocarbon receptor-deficient mice. Proc Natl Acad Sci USA 2000; 97:10442-10447.
31 Hsu YC, Kuo WR, Chen YY, Tai CF, Tsai CJ, Wang LF: Increased expression of hypoxiainducible factor lalpha in the nasal polyps. Am J Otolaryngol 2007;28:379-383.

32 Meltzer EO, Hamilos DL, Hadley JA, Lanza DC, Marple BF, Nicklas RA, et al: Rhinosinusitis: establishing definitions for clinical research and patient care. Otolaryngol Head Neck Surg 2004;131:S1-62.

33 Fokkens W, Lund V, Mullol J: European position paper on rhinosinusitis and nasal polyps 2007. Rhinol Suppl 2007:1-136.

34 Serpero L, Petecchia L, Sabatini F, Giuliani M, Silvestri M, Di Blasi P, et al: The effect of transforming growth factor (TGF)-betal and (TGF)-beta2 on nasal polyp fibroblast activities involved upper airway remodeling: modulation by fluticasone propionate. Immunol Lett 2006;105:61-67.

35 Gosepath J, Mann WJ: Current concepts in therapy of chronic rhinosinusitis and nasal polyposis. ORL J Otorhinolaryngol Relat Spec 2005;67:125-136.

36 Luo Q, Chen F, Liu W, Li Z, Xu R, Fan Y, et al: Evaluation of long-term clarithromycin treatment in adult Chinese patients with chronic rhinosinusitis without nasal polyps. ORL J Otorhinolaryngol Relat Spec 2011;73 206-211.
37 Van Bruaene N, Bachert C: Tissue remodeling in chronic rhinosinusitis. Curr Opin Allergy Clin Immunol 2011;11:8-11.

38 Hamilos DL, Leung DY, Huston DP, Kamil A, Wood R, Hamid Q: GM-CSF, IL-5 and RANTES immunoreactivity and mRNA expression in chronic hyperplastic sinusitis with nasal polyposis (NP). Clin Exp Allergy 1998;28:1145-1152.

39 Hori Y, Katoh T, Hirakata M, Joki N, Kaname S, Fukagawa M, et al: Anti-latent TGF-beta binding protein-1 antibody or synthetic oligopeptides inhibit extracellular matrix expression induced by stretch in cultured rat mesangial cells. Kidney Int 1998;53:16161625.

40 Flood-Page P, Menzies-Gow A, Phipps S, Ying S, Wangoo A, Ludwig MS, et al: AntiIL-5 treatment reduces deposition of ECM proteins in the bronchial subepithelial basement membrane of mild atopic asthmatics. J Clin Invest 2003;112:1029-1036. 